This work has been accepted for publication in JPO. Copyright may be transferred without further notice, and this version may no longer be accessible.

\title{
Adjoint Sensitivity of an Ocean General Circulation Model to Bottom Topography
}

\author{
MARTIN LOSCH \\ Alfred-Wegener-Institut für Polar- und Meeresforschung Bremerhaven, Germany
}

PATRICK HeImbach

Department of Earth, Atmospheric, and Planetary Sciences, Massachusetts Institute of Technology, Cambridge (MA), USA

\begin{abstract}
Bottom topography, or more generally the geometry of the ocean basins, is an important ingredient in numerical ocean modeling. With the help of an adjoint model, it is shown that scalar diagnostics or objective functions in a coarse resolution model, such as the transport through Drake Passage, the strength of the Atlantic meridional overturning circulation, the Deacon cell, and the meridional heat transport across $32^{\circ} \mathrm{S}$, are sensitive to bottom topography as much as they are to surface boundary conditions. For example, adjoint topography sensitivities of the transport through Drake Passage are large in choke point areas such as the Crozet-Kerguélen Plateau and south of New Zealand; the Atlantic meridional overturning circulation is sensitive to topography in the western boundary region of the North Atlantic Ocean and along the Scotland-Iceland ridge. Many sensitivities are connected to steep topography and can be interpreted in terms of bottom form stress, that is, the product of bottom pressure and topography gradient. The adjoint sensitivities are found to agree to direct perturbation methods with deviations smaller than $30 \%$ for significant perturbations on time scales of 100 years, so that the assumption of quasi-linearity that is implicit to the adjoint method holds. The horizontal resolution of the numerical model affects the sensitivities to bottom topography, but large scale patterns and the overall impact of changes in topography appear to be robust. The relative impact of changes in topography and surface boundary conditions on the model circulation is estimated by multiplying the adjoint sensitivities with assumed uncertainties. If the uncertainties are correlated in space, changing the surface boundary conditions has a larger impact on the scalar diagnostics than topography does, but the effects can locally be on the same order of magnitude if uncorrelated uncertainties are assumed. In either case, bottom topography variations within their prior uncertainties affect the solution of an ocean circulation model. To this extent, including topography in the control vector can be expected to compensate for identifiable model errors, and thus improve the solution of estimation problems.
\end{abstract}

\section{Introduction}

Numerical ocean general circulation models (OGCM) consist of a set of discretized partial differential equations for a set of prognostic variables (the numerical ocean state) which are solved subject to initial conditions and boundary conditions (lateral and surface boundary conditions, surface forcing); the solution also depends on a number of model parameters (e.g., diffusivity and viscosity parameters). These quantities are referred to as independent parameters, or con-

Corresponding author address:

M. Losch, Alfred-Wegener-Institut für Polar- und Meeresforschung Postfach 120161, 27515 Bremerhaven, Germany. (mlosch@awi-bremerhaven.de) trols. They each have associated uncertainties which can be significant. The result of an OGCM is sensitive to changes in all of these fields and parameters (e.g., Bryan 1987, Losch et al. 2004, Marsland and Wolff 2001, Simmons et al. 2004). Forcing fields, initial conditions, and parameters are derived either from measurements, reanalysis data products, estimates by different models or, if there is no information available at all, from tuning exercises such that the resulting circulation is consistent with available observations (within assumed error bars) or meets some subjective norms (expectations) of the investigator. From this perspective it is important to know which parameters influence the solution significantly, so that future efforts can be directed at estimating or measuring these parameters with higher precision. Numer- 
ous studies have explored the sensitivity of certain features of the circulation, for example the strength of the Antarctic Circumpolar Current (ACC), the Atlantic overturning circulation, to most of the above parameters or how closely the model result reproduces individual measurements or globally averaged, say, temperature profiles (e.g., Gent et al. 2001, Large et al. 1997).

The representation of the computational domain has so far received little attention in the context of uncertainty assessment of "model parameters". Although the role of topography in numerical models has been recognized for a long time (e.g., Adcroft et al. 1997, Holland 1973, Marshall 1995a, Olbers 1998, Pacanowski and Anand 1998), there is no general, objective way of representing topographic sub-grid scales on a computational grid in a way that leads to the "best possible" flow field. Topography may thus undergo a considerable amount of ad-hoc tuning before it is introduced into the OGCM. Smoothing a given topography is a widely used procedure to remove too steep gradients (Penduff et al. 2002), "holes" are filled in, straits are deepened, opened, or closed, in order to make the model produce a "more realistic" result (Large et al. 1997). In the extreme case, topography may be changed significantly so as to compensate for lacking numerics or resolution in deriving a consistent flow field. Other parameters such as the boundary conditions that apply along the lateral solid walls are equally uncertain in global ocean models (Adcroft and Marshall 1998).

Another source of uncertainty is the bathymetric data sets themselves. As an example, consider the difference between two well-known data sets: ETOPO5 (Sloss 1988) and its successor ETOPO2 (http: / / www. ngdc. noaa. $\mathrm{gov} / \mathrm{mgg} / \mathrm{fliers} / 01 \mathrm{mgg} 04 . \mathrm{html}$ ), which is in large parts based on the satellite derived topography of Smith and Sandwell (1997). The topographies implied by the two data sets are profoundly different (Fig. 1a). For visualization, the original data sets have been smoothed with a radial block mean filter of radius $112 \mathrm{~km}\left(\approx 1^{\circ}\right.$ spherical distance). The root-mean-square $(\mathrm{rms})$ difference on a $1 / 3^{\circ}$-grid over the oceans is still $131 \mathrm{~m}$ and the maximum differences are as large as $2000 \mathrm{~m}$. On large scales the topographies differ by approximately $100 \mathrm{~m}$, for example south of Australia in the Southern Ocean. Such differences are significant since they can be represented in ocean models. As a reference, Fig. 1b depicts the topography used in the present study.

State estimation based on control theory provides a natural framework for accounting for parameter uncertainties of the type discussed above (see e.g., Wunsch 1996). In this context Losch and Wunsch (2003) have explored the possibility of using bottom topography as a control variable in a barotropic shallow water model. The scope of this paper is to extend their study, and to investigate the sensitivity of the state of a given OGCM, here the MITgcm (Marshall et al. 1997), to the representation of bottom topography. In particular, (a) we show that bottom topography sensitivities in our OGCM can be computed with the help of the adjoint method, making bottom topography a possible
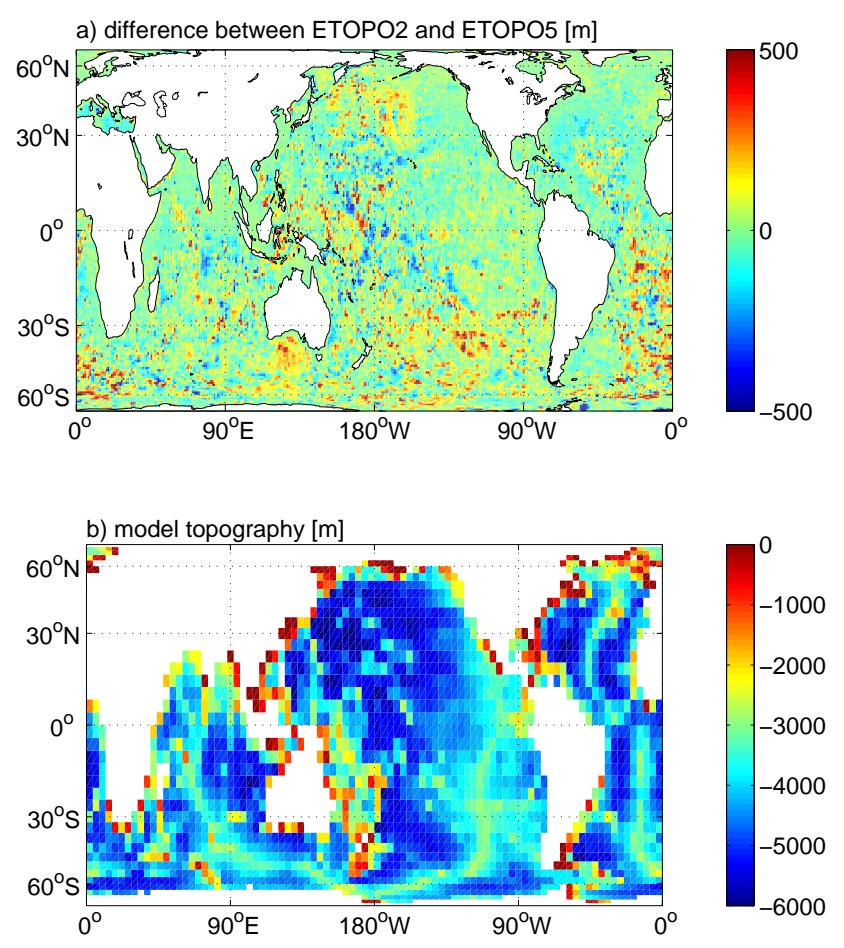

FIG. 1. a) Equal area map (Gall-Peters projection) of the difference between ETOPO2 and ETOPO5 topographies, smoothed with a $1^{\circ}$ radial block average (in units of meters). b) Model topography $H$

control variable in state estimation, (b) we quantify bottom topography sensitivities and show that they can have a significant impact on the modeled ocean circulation, (c) we put bottom topography sensitivities into context to momentum and buoyancy forcing sensitivities to assess their relative impact. The model configuration used in this work is limited by coarse resolution and crude parameterizations of sub-gridscale processes. Nevertheless, the OGCM is a fully fledged baroclinic model. In the context of sensitivity studies it has been used in this configuration in several recent studies (e.g., Ferreira et al. 2005, Huang et al. 2003, Losch et al. 2004). The implementation of bottom topography control will be shown to be significantly more complex than (i) bottom topography control in a shallow water model, and (ii) initial condition, boundary forcing, or mixing controls in a baroclinic OGCM. Therefore, our work should be viewed as an early step towards establishing topography as a control variable in an OGCM, showing the potential of this approach.

Our study hinges on the use of the adjoint method (see e.g., Wunsch 1996). This method enables us to compute, simultaneously and in a single adjoint integration, all linear sensitivities of a scalar-valued model diagnostics $J$ (often referred to as objective function, probing function, or cost function) to changes in a given set control variables $\mathbf{u}$ (for example, surface forcing, topography). The sensitivity is given by the gradient $\nabla_{u} J$ in multi-dimensional control space. In the present context, $J$ might represent volume transport through Drake Passage or the strength of the Atlantic merid- 
ional overturning circulation. This method has both technical and conceptual advantages over direct perturbation approaches but requires a separate (tedious) code development effort. Before the advent and increasing sophistication of algorithmic/automatic differentiation (AD) tools during the 1990's this development inevitably was inexact (e.g. Sirkes and Tzipermann 1997) and lagged behind the forward code development. Early OGCM studies based on hand-written adjoints include those of Tziperman and Thacker (1989), Sheinbaum and Anderson (1990) and Marotzke and Wunsch (1993). Carl Wunsch's foresight at the outset of the MITgcm development that forward and adjoint model code ought to be developed in parallel by exploiting the new technology of AD was key to what has evolved into the "Estimating the Circulation and Climate of the Oceans" (ECCO) Consortium and has lead to the adjoint capabilities of the MITgcm today.

In the following we briefly review recent OGCM applications of the adjoint method in the context of sensitivity studies (a), state estimation (b), and bottom topography control (c).

(a) The first sensitivity study using the MITgcm adjoint was undertaken by Marotzke et al. (1999), who investigated the (tangent) linear sensitivity of the meridional heat transport in the Atlantic. Bugnion (2001) and Köhl (2005) extended this study to climate time scales, and to higher-resolution, respectively. Other examples are the study of SST anomalies in the North Atlantic (Junge and Haine 2001), midlatitude-ENSO teleconnection mechanisms (Galanti and Tziperman 2003, Galanti et al. 2002), the deep ocean heat content (Huang et al. 2003), water mass origins and pathways in the Pacific (Fukumori et al. 2004), the carbon sequestration efficiency (Hill et al. 2004) in ocean models, optimal observing system design (Köhl and Stammer 2004), sensitivity of ocean biological productivity to iron fluxes (Dutkiewicz et al. 2006), and impact of open boundary conditions in a regional North Atlantic circulation (Ayoub 2005). Other groups have developed adjoint components of their OGCMs as well, and provided interesting applications of the adjoint method, for example, Galanti et al. (2002, using MOM), Weaver et al. (2003, using OPA), and Moore et al. (2004, using ROMS).

(b) With their publication of a dynamically consistent, decadal, quasi-global state estimate (see http:// www. ecco-group.org/), Stammer et al. (2002, 2003) demonstrated the practicality of solving the estimation problem of a time-dependent ocean state as laid out in Wunsch (1996) (see also Wunsch and Heimbach 2006). Subsequent global and regional-scale studies include those of Köhl and Willebrand (2003), Ferron and Marotzke (2003), Lea et al. (2006), and Gebbie et al. (2006). An important extension of the state estimation which adds transient tracers such as chlorofluorocarbons (CFCs) as observational constraints was undertaken by Li and Wunsch $(2003,2004)$.

(c) Adjoint models have been used to study bottom topography as a control variable in tidal modeling and gravity wave dynamics in shallow water models of shelf seas (Das and Lardner 1991, 1992, Heemink et al. 2002, Lardner et al. 1993, ten Brummelhuis et al. 1993). In idealized scenarios, Losch and Wunsch (2003) successfully optimized bottom topography in the limit of nearly-geostrophic dynamics by assimilating (synthetic) sea surface height data. Here we extend those approaches to a fully fledged OGCM, but restrict ourselves to adjoint sensitivity analysis. The adjoint sensitivity analysis of a realistic ocean model helps to identify physical processes within the model system and already allows us address questions in an oceanographic context.

In the future, bottom topography will likely be included in the control vector of such state estimation studies.

\section{MITgem and its adjoint}

The M.I.T. General Circulation Model (MITgcm) is a general purpose grid-point algorithm that solves the Boussinesq form of the Navier-Stokes equations for an incompressible fluid, hydrostatic or fully non-hydrostatic, with a spatial finite-volume discretization on a curvilinear computational grid (in the present context on a three-dimensional longitude, latitude, depth grid). The model algorithm is described in Marshall et al. (1997); for online documentation and access to the model code, see MITgcm Group (2002).

The tangent linear and adjoint model of MITgem are generated via automatic/algorithmic differentiation (AD) (Griewank 2000). To this end, the MITgcm has been adapted for use with the Tangent linear and Adjoint Model Compiler (TAMC), and its successor TAF (Transformation of Algorithms in Fortran, Giering and Kaminski 1998) to provide exact, efficient tangent-linear and adjoint code (Heimbach et al. 2002, 2005, Marotzke et al. 1999). The adjoint model framework incorporates the ECCO state estimation infrastructure, but only part of it here because we restrict ourselves to sensitivity studies.

\section{a. Some aspects of bottom topography control}

The starting point for our adjoint code development was the adjoint model used in previous sensitivity and state estimation studies which computes the local gradient of the objective function with respect to a (by now "standard") control vector comprising initial temperature and salinity as well as air-sea buoyancy and momentum flux fields (other control variables are available, but do not play a role here).

The procedure for adding topography to the control vector is based on the "partial cell" treatment in the MITgcm (Adcroft et al. 1997). This technique enables continuous variation of the fractional volume per grid cell between zero and one with respect to the vertical component and - apart from its original motivation to represent topography more accurately without increasing the vertical resolution - ensures differentiability in the cells abutting topography. Total depth $H$ is then written as the sum over all tracer cells

$$
H(i, j)=\sum_{k} h_{c}(i, j, k) \Delta r_{f}(k),
$$


where $\Delta r_{f}(k)$ denotes the full-cell thickness of layer $k$ and $h_{c}(i, j, k)$ the fractional cell thickness at the tracer point of the C-grid. Denoting the bottom layer at $(i, j)$ as $k_{\text {low }}$, the $h_{c}(i, j, k)$ assume values

$$
h_{c}(i, j, k) \quad \begin{cases}=1, & \text { for } k<k_{\text {low }} \\ =h_{\text {low }}(i, j) \in(0,1] & \text { for } k=k_{\text {low }} \\ =0, & \text { for } k>k_{\text {low }}\end{cases}
$$

From these, fractional thicknesses are derived for the cell faces which carry the zonal ( $u$ at $W$-face) and meridional ( $v$ at $S$-face) velocity points on the C-grid, $h_{w}(i, j, k), h_{s}(i, j, k)$, respectively. The fractional elements $h_{x}(i, j, k), x=c, w, s$ are central to the finite-volume spatial discretization. For more details on partial cells we refer to Adcroft et al. (1997) and MITgcm Group (2002).

The variation of Eq. (2) yields $\delta h_{c}(i, j, k)=$ $\delta h_{\text {low }}(i, j) \delta_{k k_{\text {low }}}$, with the Kronecker delta symbol $\delta_{k k_{\text {low }}}$, and thus variation of Eq. (1) reduces to

$\delta H(i, j)=\sum_{k} \delta h_{c}(i, j, k) \Delta r_{f}(k)=\delta h_{\text {low }}(i, j) \Delta r_{f}\left(k_{\text {low }}\right)$

Thus, while formulating the control problem in terms of the full depth $H$ and 3-dimensional field $h_{c}(i, j, k)$, when taking the derivative all terms in the sum (1) vanish except the bottom layer cell $k=k_{\text {low }}$. The source of the adjoint bottom topography sensitivity is thus confined to the bottom layer, and propagated into the interior solely by adjoint variables of the time-dependent flow field (in the language of AD, while the interior $\left(k \neq k_{\text {low }}\right)$ cell thicknesses are active, their sensitivities evaluate to zero, and only $k=k_{\text {low }}$ is effectively active).

The tangent-linear model (the adjoint of which is very closely related, see e.g., Giering and Kaminski 1998) depends on the particular choice of which fields are considered as control variables, that is, whether a field is considered constant (passive) or variable (active) with respect to differentiation.

Consider a tracer cell face area normal to the $x$ (zonal) direction, $A_{x}=\Delta y \Delta r_{f} h_{w}$, with meridional arc length $\Delta y$. Then, the zonal volume transport $U$ through the cell face $A_{x}$ is given by

$$
U=u A_{x}
$$

In the absence of bottom topography control, this represents a linear expression in $u$ with constant $A_{x}$, and linearization trivially yields $\delta U=\delta u A_{x}$. However, if $h_{c}$ is allowed to vary, then $h_{w}$ varies and Eq.(3) is quadratic, so that linearization requires the product rule, thus

$$
\delta U=\delta u A_{x}+u \delta A_{x}
$$

where $\delta A_{x}=\Delta y \Delta r_{f} \delta h_{w}$. Recalling Eq. (2), we note that $\delta A_{x}=0$, except at $k=k_{\text {low }}$. All advective terms are affected and will propagate changes in fractional cell thicknesses. In a similar fashion, linearization of viscous fluxes
(Laplacian and biharmonic friction), bottom and side drag terms will be modified.

Modifications in the MITgcm to account for the activity of partial cells (which are passive parameters if bottom topography is not a control) are mostly straightforward, with one exception: The conjugate gradient elliptic solver loses its self-adjoint property which had made it easy to deal with previously (Marotzke et al. 1999). We point out that changes necessary in the model to recover a correct adjoint were substantial, and qualitatively different from code modifications to accommodate the "standard" control variables. Nevertheless, we confine this technical discussion to the appendix.

\section{Adjoint Sensitivity Simulations to Bottom Topography}

In this first study of adjoint bottom topography sensitivities of a fully-fledged baroclinic OGCM, we restrict ourselves to a coarse-resolution setup. This enables us to conduct a larger (and longer) number of simulations as well as longer simulations to elicit general magnitudes and patterns of sensitivities. The configuration of the OGCM is very similar to that of Ferreira et al. (2005). It covers the globe from $80^{\circ} \mathrm{S}$ to $80^{\circ} \mathrm{N}$ with a horizontal resolution of $4^{\circ} \times 4^{\circ}$ and 15 layers with thicknesses ranging from $50 \mathrm{~m}$ near the surface to $690 \mathrm{~m}$ near the bottom. To concentrate on bottom topography effects, the model is forced with annual means of wind forcing fields (Trenberth et al. 1990) and heat and freshwater fluxes (Jiang et al. 1999) for most experiments. No temperature or salinity relaxation to climatology is applied. The topography is derived from ETOPO2 by horizontal smoothing with an averaging kernel with a radius of $230 \mathrm{~km}$ and interpolated to the $4^{\circ}$-grid. The only additional editing of topography involves the Drake Passage: it is deepened by resetting 12 grid points to $3870 \mathrm{~m}$ and and 2 to $4510 \mathrm{~m}$, to allow a more realistic transport through the strait in the coarse resolution model. These modifications do affect the circulation, but do not alter the qualitative picture of our sensitivity results. The topography used is shown in Fig. 1 b.

To avoid problems with vigorous initial adjustment processes, all model integrations are started from a 2000 year spin-up integration that was initialized with temperature and salinity climatologies (Levitus and Boyer 1994, Levitus et al. 1994). Again, this choice has little impact on the overall patterns of the sensitivities. For computational efficiency, all integrations use asynchronous time stepping with a tracer time step of 2 days and a momentum time step of 20 minutes. Preliminary test showed that neither the horizontal distribution nor the magnitude of the sensitivity maps are greatly affected by this choice (not shown) as long as the integration times are longer than gravity-wave time scales.

For comparison, we use a configuration with a horizontal resolution of $2^{\circ}$ and 23 vertical layers ranging from $10 \mathrm{~m}$ near the surface to $500 \mathrm{~m}$ at depth, similar to the one used in Stammer et al. (2002), and driven with the same surface forcing as the $4^{\circ}$-model. 
TABLE 1 . Summary of adjoint sensitivity calculations

\begin{tabular}{|c|c|c|c|c|c|}
\hline objective function & 1 year & 10 years & 100 years & 500 years & 1000 years \\
\hline \multicolumn{6}{|l|}{$\left(4^{\circ}\right.$ resolution $)$} \\
\hline $\begin{array}{l}\text { Drake Passage trans- } \\
\text { port }\end{array}$ & DPT4D1Y & DPT4D10Y & DPT4D100Y & DPT4D500Y & DPT4D1000Y \\
\hline $\begin{array}{l}\text { Atlantic Meridional } \\
\text { Overturning }\end{array}$ & MOC4D1Y & MOC4D10Y & MOC4D100Y & DTP4D500Y & MOC4D1000Y \\
\hline $\begin{array}{l}\text { Southern } \\
\text { overturning }\end{array}$ & SOO4D1Y & SOO4D10Y & SOO4D100Y & DTP4D500Y & \\
\hline $\begin{array}{l}\text { Southern Ocean heat } \\
\text { uptake }\end{array}$ & SOH4D1Y & SOH4D10Y & SOH4D100Y & SOH4D500Y & \\
\hline$\left(2^{\circ}\right.$ resolution $)$ & & & & & \\
\hline $\begin{array}{l}\text { Drake Passage trans- } \\
\text { port }\end{array}$ & DPT2D1Y & DPT2D10Y & & & \\
\hline $\begin{array}{l}\text { Atlantic Meridional } \\
\text { Overturning }\end{array}$ & MOC2D1Y & MOC2D10Y & & & \\
\hline
\end{tabular}

We have conducted a series of adjoint sensitivity calculations for a set of dynamically interesting scalar model diagnostics (objective functions) which are subject of frequent oceanographic and climate analyses. A summary is given in Table 1. In the following we discuss mainly experiments with (adjoint) integration times of 100 years.

\section{a. Drake Passage Transport}

The volume transport through Drake Passage averaged over the last year of the 100-year-integration is chosen as a scalar measure (objective function) for the strength of the ACC. In our model simulation this transport is low (76 Sv), which is in part attributed to the surface forcing (with monthly-varying climatological fluxes and sea surface temperature restoring the transport rises to $102 \mathrm{~Sv}$, not shown). Fig. 2a shows maps of the sensitivity of the Drake Passage transport with respect to bottom topography for an integration of 100 years.

The sensitivity to bottom topography is localized and the global map is not smooth. In general, the flow is affected by topography gradients, and small variations in absolute depth are less important. For example, in a zonal integral along a latitude circle (or a closed streamline), momentum input by surface wind stress is balanced to a good approximation by topographic or bottom form stress (bottom pressure times horizontal topography gradient $p_{b} \nabla H$, Olbers 1998). Overlaying the topography with sensitivity to topography shows that changing the topography according to the sign of the sensitivity generally tends to reduce the zonal topographic gradients. As an example a section along $50^{\circ} \mathrm{S}$ is shown in Fig. 3. Smoother topography leads to less bottom form stress and allows the flow to accelerate.

In coarse-resolution models as discussed here, topography gradients cannot be realistically resolved in general, and are often represented by two adjacent grid points. Therefore, if reducing the topographic gradients has an effect on the objective function, adjacent grid points can have sensitivities

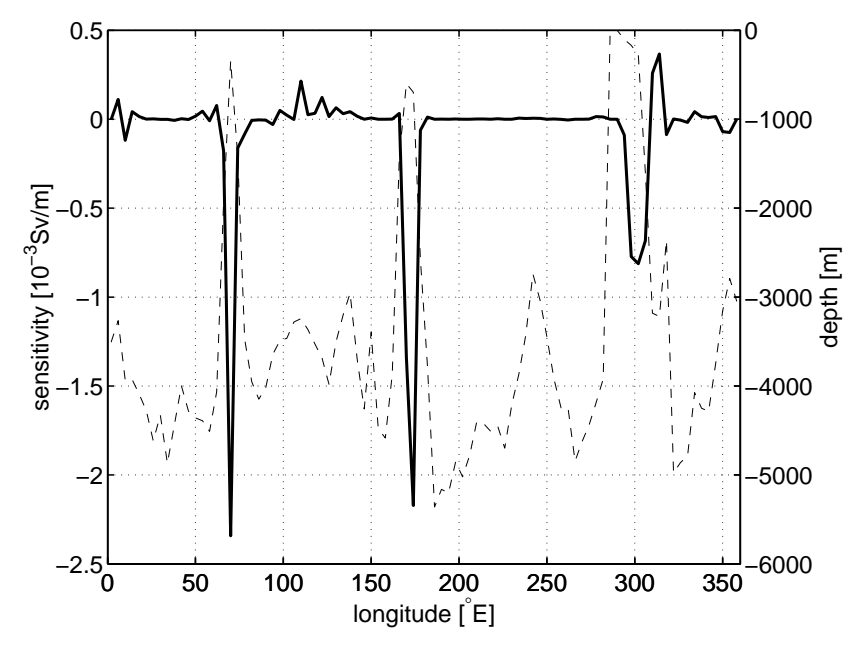

FIG. 3. Depth (thin dashed line, in $\mathrm{m}$ ) and sensitivity (thick solid line, in $\mathrm{Sv} / \mathrm{m}$ ) of the Drake Passage transport to topography along $50^{\circ} \mathrm{S}$.

with opposite signs (cf. Fig. 3). If the topography is resolved by the grid, these dipole pattern are still present, but on larger scales than the grid scale (see Figure 3 in Losch and Wunsch 2003). In Section 4 we will see that the sensitivities do depend on the grid resolution. With higher resolution they are concentrated near continental slopes and generally over steep topography.

The sensitivity to topography is concentrated at a few "choke points" in the Southern Ocean with steep topography: Drake Passage, Crozet-Kerguélen Plateau, and the Indian Southpolar Ridge/Macquarie Ridge/New Zealand Plateau area south of New Zealand. Decreasing the height $H$ of the topography in the latter two regions leads to higher Drake Passage transports as one would expect from simple geostrophic contour considerations: "flatter" topography leads to less blocked geostrophic contours, which in turn allows a higher transport. In a different language, the momentum input by surface stress is balanced in the closed stream- 
a) Drake Passage, $\partial \phi / \partial \mathrm{H}\left[10^{-3} \mathrm{~Sv} / \mathrm{m}\right]$

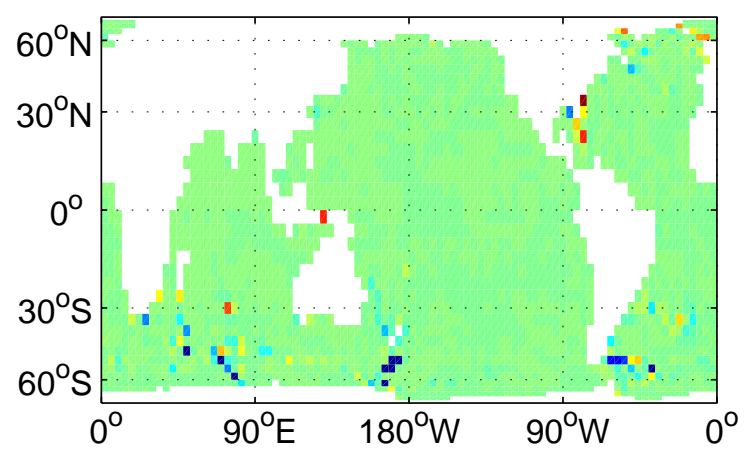

c) Deacon Cell, $\partial \phi / \partial \mathrm{H}\left[10^{-5} \mathrm{~Sv} / \mathrm{m}\right]$

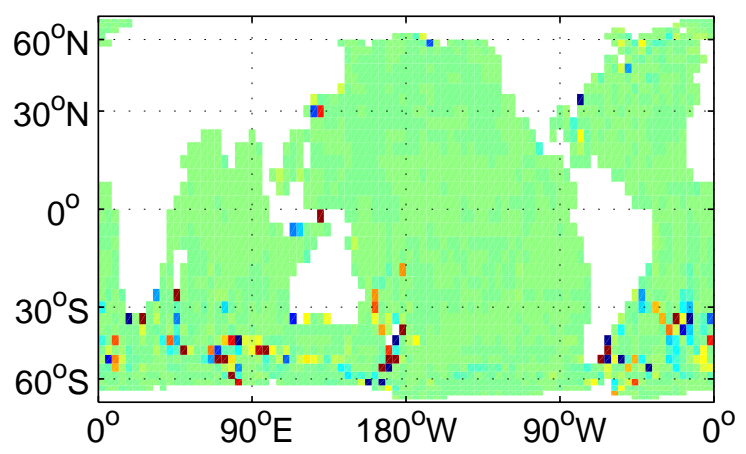

b) Atlantic MOC, $\partial \phi / \partial \mathrm{H}\left[10^{-4} \mathrm{~Sv} / \mathrm{m}\right]$

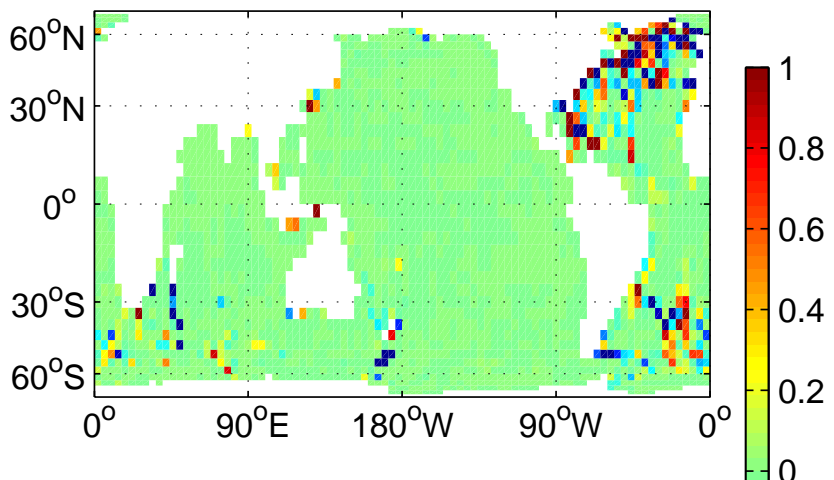

d) heat transport across $32^{\circ} \mathrm{S},\left[10^{-6} \mathrm{PW} / \mathrm{m}\right]$

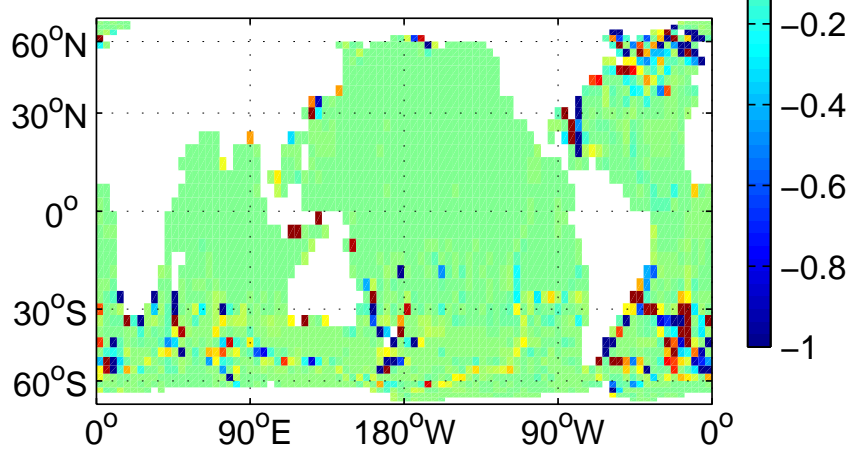

FIG. 2. Adjoint sensitivity with respect to topography of a) the volume transport through Drake Passage, b) the Atlantic meridional overturning circulation (MOC), c) the Deacon cell, and d) the heat transport across $32^{\circ} \mathrm{S}$. In all cases, the integration period is 100 years.

line average by bottom form stress, that is, by the average of the product of bottom pressure and the gradient of topography (Olbers 1998). Decreasing the horizontal (alongstreamline) topography gradient reduces the form stress term so less momentum taken out of the system than added, thus increasing the transport. In the Drake Passage the situation is not so obvious, but the sensitivities can be understood using the same arguments. The ACC turns north onto the Argentinean Plateau just after the Drake Passage. Decreasing the topographic gradient along its streamlines can be achieved either by increasing the height of the topography (positive sensitivity) directly in the passage and across the Scotia Ridge where the ocean is deepest or by decreasing the height near South Georgia and at the southern rim of the shallow Argentinean Plateau. Therefore the sensitivities have opposite signs in this region. The positive sensitivities at $50-46^{\circ} \mathrm{W}$ and $50^{\circ} \mathrm{S}$ correspond to a sharp drop in topography (cf. Fig. 3).

\section{b. Atlantic Meridional Overturning Stream Function}

The adjoint sensitivity of the strength of the Atlantic meridional overturning circulation (MOC) averaged over the last year of a 100 year integration is shown in Fig. 2b. We define the strength of the MOC as the maximum value of the overturning stream function at $32^{\circ} \mathrm{N}$, which happens to be at $1080 \mathrm{~m}$ depth (the bottom of the 7 th model layer). The MOC is somewhat overestimated with $29 \mathrm{~Sv}$; we attribute this strong overturning mainly to inappropriate surface boundary conditions (constant heat and fresh water fluxes, no restoring), the coarse resolution, and the parameterization of convection by increased vertical diffusivity.

The peak values of the sensitivity to topography are $8 \times 10^{-3} \mathrm{~Sv} \mathrm{~m}^{-1}$ but the color scale in Fig. $2 \mathrm{~b}$ is chosen to emphasize smaller values in the Southern Ocean. Strong topography sensitivities on the order of $10^{-3} \mathrm{~Sv} \mathrm{~m}^{-1}$ near Newfoundland and along the path of the Gulf Stream and the North Atlantic current show that the position of both the upper branch of the overturning circulation (the Gulf Stream/North Atlantic Current) and the lower branch (Deep Western Boundary Current) in part determine the overturning strength (see also Fig. 5 in Section 4 Section c). Both branches are boundary currents (barely resolved in the present configuration) that are strongly influenced by topography. Because of the chosen color scale, many second order features appear in the North Atlantic that are difficult to interpret. In Section 4 we will see that these patterns depend strongly on the horizontal resolution.

The MOC sensitivities in the Southern Ocean are weaker than Drake Passage transport sensitivities in the Southern ocean (note that the color scale is different by one order of magnitude to account for the much weaker MOC sensitivities) because (i) the Southern Ocean has a only a remote 
influence on the MOC (diffusive processes weaken this influence), but a more direct influence on ACC transport, and (ii) the time scale of 100 years may not be not long enough to propagate the entire adjoint signal from the North Atlantic to the Southern Ocean. However, the topography sensitivities in the Southern Ocean have a pattern that is similar to that of the Drake Passage transport (Fig. 2a) suggesting that a stronger overturning is connected to a stronger ACC, as proposed by Toggweiler and Samuels (1995). Zonal wind stress sensitivity patterns in the Southern Ocean (not shown) are also similar to the Drake Passage case (see Section 5) and thereby support this interpretation.

\section{c. Overturning and Meridional Heat Transport in the Southern Ocean}

The Southern Ocean overturning or Deacon cell (e.g., Döös and Webb 1994, Speer et al. 1999) is the secondary circulation in the Southern Ocean (the ACC being the primary one). In the zonal Eulerian mean, it consists of a northward Ekman transport, which is the main driver of the Deacon cell, a downwelling branch north of the Drake Passage latitude, a deep return flow, below the topography and geostrophically balanced, and an upwelling branch around Antarctica which ventilates deep waters from the north. This overturning circulation has been subject to many studies (see Olbers et al. 2004, for a review). In coarse resolution models with Gent and McWilliams (1990, GM) parameterization of the eddy fluxes the Deacon cell is eliminated as a tracer transport agent (Borowski et al. 2002), but in our configuration without GM-parameterization, the Deacon cell is rather strong (44 Sv).

Connected to the overturning circulation, the surface heat flux in the Southern Ocean cannot be observed directly. Models and indirect data have been used to estimate the heat budget in the Southern Ocean (e.g., Ganachaud and Wunsch 2000, Sloyan and Rintoul 2001, Trenberth and Caron 2001, Wunsch 2005). Flux estimates range from -0.6 to $-0.9 \mathrm{PW}$ across $32^{\circ} \mathrm{S}$ implying a poleward flux of heat (Trenberth and Caron 2001, Wunsch 2005).

In our simplified model, the heat flux at the surface is prescribed. In a steady state and in the absence of further heat sources, the northward heat transport across a given latitude is balanced by the integrated surface heat flux north of that latitude. The forcing data (Jiang et al. 1999) used in this study imply a mean southward transport of $0.45 \mathrm{PW}$ across $32^{\circ} \mathrm{S}$ consistent with the observed value in the model, and within errors of estimates of Wunsch (2005) and references cited therein. Also the partition of the transport between the ocean basin shows the observed pattern with northward transport in the Atlantic $(0.57 \mathrm{PW})$ and Pacific Oceans $(0.23 \mathrm{PW})$ and southward transport of $1.25 \mathrm{PW}$ in the Indian Ocean (e.g., Ganachaud and Wunsch 2000, Sloyan and Rintoul 2001).

The sensitivity of the Deacon cell, which we define as the maximum overturning strength at $48^{\circ} \mathrm{S}$ and $50 \mathrm{~m}$ depth (bot- tom of the top layer of the model), is shown in Fig. 2c. The pattern of the overturning sensitivity to topography is similar to that for the Drake Passage transport (Fig. 2a) but often with reversed sign. (Note also that the sensitivities are two orders of magnitude smaller than those for the Drake Passage transport.) For example increasing the height of topography (i.e., making the ocean shallower) south of New Zealand or at the Crozet-Kerguélen Plateau increases the overturning strength but decreases the Drake Passage transport. On the other hand, the sensitivity along the mid-ocean ridges has the same sign in most places, so that increasing the height of the mid-ocean ridge in the South Pacific again decreases the Drake Passage transport, but now also decreases the Deacon cell. We leave the interpretation of this ambiguous result until we have a solution with higher resolution and a better parameterization of eddy transfer processes.

The sensitivity of the advective heat transport across $32{ }^{\circ} \mathrm{C}$ to bottom topography is shown in Fig. $2 \mathrm{~d}$. Note that the heat transport sensitivity is measured in $\mathrm{PW} \mathrm{m}^{-1}$, while the overturning sensitivity is in $\mathrm{Sv} \mathrm{m}^{-1}$. In spite of the different units, the sensitivity to topography is strong in locations similar to the ones for Deacon cell and heat transport, supporting the connection between these quantities. However, more often than not, the sign of the heat transport sensitivity is opposite to that of the overturning sensitivity, because a stronger general circulation increases the overturning and the southward heat transport, hence decreases the northward heat transport. Therefore, weaker western boundary currents, the main agents of southward heat transport in the Southern Ocean increases the northward heat transport.

\section{Linearity, time scales, and horizontal resolution}

In the following we assess the degree to which the implicit assumption of linearity holds, and investigate the dependency of the sensitivity patterns with respect to integration times, and horizontal resolution.

\section{a. Finite difference perturbation experiments}

The adjoint method implies linearization about the state of the model so that the adjoint sensitivities are always linear sensitivities. The assumption of quasi-linearity is tested in the following by a small sample of perturbation experiments.

It is important to understand the difference between what is usually called gradient checks and testing quasi-linearity. Gradient checks test individual elements of the adjointgenerated gradient $\left(\nabla_{u_{i}} J\right)_{a d j}$. against finite-difference integrations in the limit of small perturbations, $\epsilon$, in the corresponding control vector element and for short integration times, $\left(\nabla_{u_{i}} J\right)_{f . d .}=\left[J\left(u_{i}+\epsilon\right)-J\left(u_{i}\right)\right] / \epsilon$. We performed various gradient checks to verify the accuracy of the automatically generated adjoint code, but will omit technical details. Instead we focus here on testing quasi-linearity: we use large finite perturbations and long time scales to assess to what degree the assumption of linearity, that is implicitly 
made when dealing with adjoint sensitivities, is valid.

We choose four different points where we add a perturbation of $100 \mathrm{~m}$ to the height of the topography (making the ocean locally shallower): Indonesian Throughflow $\left(130^{\circ} \mathrm{E}\right.$, $\left.2^{\circ} \mathrm{S}\right)$, Macquarie Ridge $\left(166^{\circ} \mathrm{E}, 54^{\circ} \mathrm{S}\right)$, exit of Labrador Sea $\left(42^{\circ} \mathrm{W}, 54^{\circ} \mathrm{N}\right)$, and a point in the North Pacific Ocean $\left(142^{\circ} \mathrm{W}, 38^{\circ} \mathrm{N}\right)$ with very low sensitivity. We compare the resulting differences to a reference run with the original topography to the linear adjoint sensitivities in Table 2 .

Adjoint and finite-difference sensitivities give the same order of magnitude transport differences. The adjoint sensitivity results differ by less than $30 \%$ from the perturbation results except for cases when the sensitivity is very small and the implied transport changes smaller than $0.001 \mathrm{~Sv}$. Decreasing the integration time decreases the differences further (e.g., to order $5 \%$ for 1 year integrations). We conclude that on time scales of 100 years, the adjoint sensitivities can be used to estimate the impact of finite topography uncertainties on scalar model diagnostics within roughly $30 \%$.

\section{b. Different Time Scales}

Fig. 4 shows that the sensitivity to topography changes with the length of the integration: as an example, we choose as the objective function the meridional heat transport across $32^{\circ} \mathrm{S}$, averaged over the last year of the integration and integrate the model for $1,10,100$, and 500 years. The topography sensitivity changes in pattern and magnitude for the first three integrations, but there are only small differences between the 100 year and the 500 year run, mostly restricted to regions far away from $32^{\circ} \mathrm{S}$. Again, the effect of local vs. remote effects is visible, the former playing a dominant role for short integration times (1 year), the latter increasing in influence with increasing time scales (100, 500 years).

In forward perturbation experiments such as the ones in Section $3 \mathrm{a}$, we found that the difference in, for example, temperature between two simulations, albeit two to three orders of magnitude smaller than the signal, has not reached a steady state after 500 years. Because the model includes a parameterization of convection, we expect non-linear behavior to maintain small differences between the experiments, even in our coarse configurations: small differences in buoyancy cause different convective depths, that lead to new anomalies that are propagated by Rossby and Kelvin waves. Therefore, small changes in sensitivity near the "measurement" area along $32^{\circ} \mathrm{S}$, where the objective function is computed, are not surprising even after long time scales, but are a consequence of the internal variability of the model.

We conclude that after 100 years the sensitivities near the location of the "measurement" have nearly equilibrated and that the sensitivities of the 100 year-integrations are representative of principle sensitivity patterns.

\section{c. Higher Resolution}

The sensitivity to bottom topography is expected to depend in part on the horizontal resolution - because with varying resolution, the topographic gradients and the sub-grid-scale processes that are implicitly parameterized, change. Therefore, increasing the resolution from $4^{\circ}$ to $2^{\circ}$ should decrease the sensitivity. Doubling the resolution requires a shorter time step so that the overall computational cost (wall clock time and memory requirements) for a $2^{\circ}$ experiment is at least 16 times that of the $4^{\circ}$ experiment. For this reason, we compare only shorter 1 and 10 -year integrations of a $4^{\circ}$ experiment to a $2^{\circ}$ experiment in Fig. 5 for the objective function Atlantic meridional overturning stream function.

As expected the sensitivities in the $2^{\circ}$ experiments and in the $4^{\circ}$ experiments are different. For example, the sensitivity of the Drake Passage transport over the Crozet-Kerguélen Plateau is less pronounced in the $2^{\circ}$ resolution run, because at this resolution the topography resolves a few passages below $2000 \mathrm{~m}$ depth and hence the ACC feels less topographic stress: the ACC is steered around the Kerguèlen Plateau and not across it as in the coarser and more viscous experiment (not shown).

The MOC sensitivities in the North Atlantic Ocean are much finer in the the $2^{\circ}$ run. As the continental margins and the boundary currents become sharper, so does the sensitivity to topography. The sensitivity in the interior of the North Atlantic basin that is visible in the $4^{\circ}$ run has vanished, pointing towards too strong horizontal viscosity/diffusion in the coarser experiment: with strong internal friction, the boundary currents are more spread-out and are also affected by topography in the interior.

In spite of these differences, several important patterns do appear to be robust. For example, the sensitivities in both configurations are pronounced along the western boundary of the North Atlantic and after 10 years also in the Denmark Strait and over the Scotland-Iceland Ridge. This similarity is encouraging and shows that the $4^{\circ}$ runs do contain relevant sensitivity patterns.

From the graphs in Fig. 5, the point-wise sensitivities in the coarse runs appear to be larger in both amplitude and spatial extent. To estimate the overall effect of the sensitivities, the sensitivities $\partial \phi / \partial u_{i}$ at position $i$ are multiplied by the uncertainties $\Delta u_{i}$ :

$$
\Delta \phi_{i}=\frac{\partial \phi}{\partial u_{i}} \Delta u_{i}
$$

In the limit of uncorrelated uncertainties, the point-wise contributions $\Delta H \partial \phi / \partial H$ are added geometrically according to uncorrelated error propagation $\left(\Delta \phi=\sqrt{\sum_{i} \Delta \phi_{i}^{2}}\right)$ : the effect of an uncorrelated global topography uncertainty of $\Delta H=100 \mathrm{~m}$ would result in an uncertainty of the transport through Drake Passage by $1 \mathrm{~Sv}$ in the $2^{\circ}$ experiment and $0.6 \mathrm{~Sv}$ in the $4^{\circ}$ experiment. For the meridional overturning strength, the estimated uncertainties are $0.4 \mathrm{SV}$ and $0.6 \mathrm{~Sv}$ respectively. In the other limit of perfect correlation, 
TABLE 2. Comparison of implied transport difference from linear adjoint sensitivities $\Delta \phi_{\mathrm{adj}}=\Delta H \cdot(\partial \phi / \partial H)$ and perturbation experiments $\Delta \phi_{\mathrm{fwd}}=\phi(H+\Delta H)-\phi(H)$ for 100 year integrations. The relative difference is $\left[\left(\Delta \phi_{\mathrm{adj}}-\Delta \phi_{\mathrm{fwd}}\right) / \Delta \phi_{\mathrm{fwd}}\right] \times 100$.

\begin{tabular}{|c|c|c|c|c|}
\hline & $130^{\circ} \mathrm{E}, 2^{\circ} \mathrm{S}$ & $166^{\circ} \mathrm{E}, 54^{\circ} \mathrm{S}$ & $142^{\circ} \mathrm{W}, 38^{\circ} \mathrm{N}$ & $42^{\circ} \mathrm{W}, 54^{\circ} \mathrm{N}$ \\
\hline \multicolumn{5}{|c|}{ Drake Passage transport (DPT4D100Y) } \\
\hline$\Delta \phi_{\mathrm{fd}}[\mathrm{Sv}]$ & 0.0822 & -0.1885 & $-2 \times 10^{-6}$ & -0.0250 \\
\hline$\Delta \phi_{\text {adj }}[\mathrm{Sv}]$ & 0.0632 & -0.1533 & $-7 \times 10^{-7}$ & -0.0253 \\
\hline rel. diff. [\%] & 23 & 19 & 69 & 1 \\
\hline \multicolumn{5}{|c|}{ Atlantic meridional overturning circulation (MOC4D100Y) } \\
\hline$\Delta \phi_{\mathrm{fd}}[\mathrm{Sv}]$ & 0.0386 & -0.0139 & $6 \times 10^{-7}$ & -0.0590 \\
\hline$\Delta \phi_{\text {adj }}[\mathrm{Sv}]$ & 0.0286 & -0.0141 & $3 \times 10^{-7}$ & -0.0611 \\
\hline rel. diff. $[\%]$ & 26 & 1 & 46 & 4 \\
\hline \multicolumn{5}{|c|}{ "Deacon Cell" (SOO4D100Y) } \\
\hline$\Delta \phi_{\mathrm{fd}}[\mathrm{Sv}]$ & 0.0026 & 0.0092 & $-7 \times 10^{-7}$ & 0.0001 \\
\hline$\Delta \phi_{\text {adj }}[\mathrm{Sv}]$ & 0.0023 & 0.0096 & $-8 \times 10-8$ & 0.0001 \\
\hline rel. diff. [\%] & 10 & 5 & 89 & 33 \\
\hline \multicolumn{5}{|c|}{ Heat transport across $32^{\circ} \mathrm{S}(\mathrm{SOH} 4 \mathrm{D} 100 \mathrm{Y})$} \\
\hline$\Delta \phi_{\mathrm{fd}}[\mathrm{Sv}]$ & 0.0019 & -0.0006 & $-3 \times 10^{-7}$ & 0.0003 \\
\hline$\Delta \phi_{\text {adj }}[\mathrm{Sv}]$ & 0.0010 & -0.0007 & $-7 \times 10^{-8}$ & 0.0002 \\
\hline rel. diff. [\%] & 44 & 21 & 80 & 19 \\
\hline
\end{tabular}

that is by simply adding all $\Delta \phi_{i}$ in Eq. (5), the implied uncertainties are $-4.4 \mathrm{~Sv}$ for the $2^{\circ}$ experiment and $-2.0 \mathrm{~Sv}$ for the $4^{\circ}$ experiment for the Drake Passage case. For the $\mathrm{MOC}$, we have $0.16 \mathrm{~Sv}$ for the $2^{\circ}$ experiment, $-1.6 \mathrm{~Sv}$ for the $4^{\circ}$ experiment. These numbers are ambiguous and do not support the hypothesis that the overall sensitivity to topography is smaller in high resolution models. All that can be said is, that the sensitivities to topography do change with resolution, and more experiments are needed to explore the sensitivities at higher resolutions.

\section{Importance Relative to Momentum and Buoyancy Forcing}

To put adjoint sensitivities with respect to bottom topography into perspective, we show the sensitivity of the Drake Passage transport to the control variables zonal and meridional wind stress, heat and fresh water flux in Fig. 6.

The zonal wind stress sensitivity map shows that increasing the zonal wind stress in the Southern Ocean, in particular in Drake Passage itself, south of Africa and Australia, increases the transport through the Drake Passage (positive sensitivity). This is accomplished by an increased Ekman transport piling up surface waters at northern boundaries (Drake Passage, Africa, and Australia). The increased surface height gradient then accelerates the ACC. Less northward (i.e., more southward) meridional wind stress along the Pacific coast of South America moves less water out of ("pushes" more water into) the Antarctic Circumpolar Current, thus increasing its strength (negative sensitivity). The northern hemisphere wind stress does not seem to affect the ACC as much on the time scale of 100 years.

Heat and fresh water fluxes are converted to buoyancy fluxes by scaling with $g \alpha_{\theta} /\left(\rho_{0} c_{w}\right)$ and $g \beta_{S} S_{0}$, respectively. Upward flux (out of the ocean) is positive. The parameters are the gravity acceleration $g=9.81 \mathrm{~m} \mathrm{~s}^{-2}$, the thermal expansion coefficient $\alpha_{\theta}=2 \times 10^{-4} \mathrm{~K}^{-1}$, the saline contraction coefficient $\beta_{S}=7.4 \times 10^{-4}$, the heat capacity of water $c_{w}=3994 \mathrm{~J} \mathrm{~kg}^{-1} \mathrm{~K}^{-1}$, a reference density $\rho_{0}=$ $1035 \mathrm{~kg} \mathrm{~m}^{-3}$, and a reference salinity $S_{0}=35$. In buoyancy flux units, it becomes immediately clear that heat and freshwater fluxes have very similar effects on the Drake Passage transport, and their effect can be interpreted as a general sensitivity to buoyancy fluxes. The physical interpretation is also intuitive: decreasing the outgoing buoyancy flux north of approximately $50^{\circ} \mathrm{S}$ increases the buoyancy of the surface layers, thus the stratification; south of $50^{\circ} \mathrm{S}$ increased upward buoyancy flux decreases the buoyancy around Antarctica. Both mechanisms increase the meridional density gradient, which then accelerates the ACC. The sensitivity in the northern hemisphere is much larger (more negative) in the Atlantic Ocean than in the remaining oceans pointing to an intimate link between the Atlantic Overturning Circulation and the strength of the ACC.

In the Southern Ocean, mean wind stress values are on the order of $0.1 \mathrm{~N} \mathrm{~m}^{-2}$, surface buoyancy fluxes range from -5 to $+5 \times 10^{-8} \mathrm{~m}^{2} \mathrm{~s}^{-3}$. Assume uncertainties as large as $50 \%$ for wind stress and buoyancy fluxes; uncertainty of topography is estimated at $100 \mathrm{~m}$ (locally the uncertainties can be much larger, cf. Fig. 1a). From Fig. 6, we read off a zonal wind stress sensitivity of $2 \mathrm{~Sv} /\left(\mathrm{N} \mathrm{m}^{-2}\right)$ in Drake Passage, a buoyancy flux sensitivity of $1 \times 10^{7} \mathrm{~Sv} /\left(\mathrm{m}^{2} \mathrm{~s}^{-3}\right)$ in the Atlantic Ocean, and from Fig. 2 a topography sensitivity of $2 \times 10^{-3} \mathrm{~Sv} / \mathrm{m}$ near the Crozet-Kerguèlen Plateau. According to Eq. (5), changing the control variables in these points by their respective large uncertainties changes the Drake 
1 year

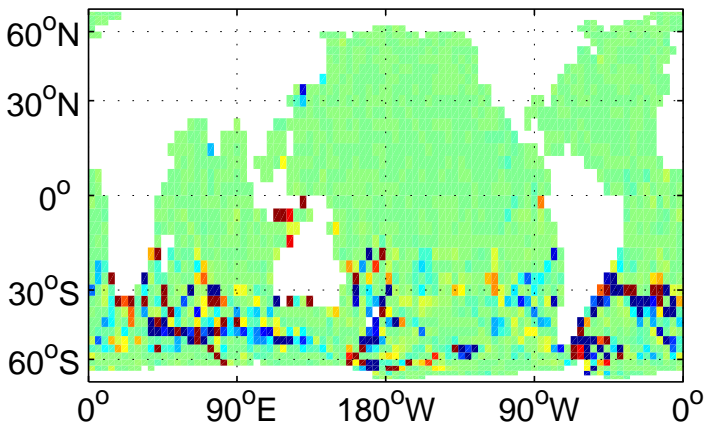

100 years

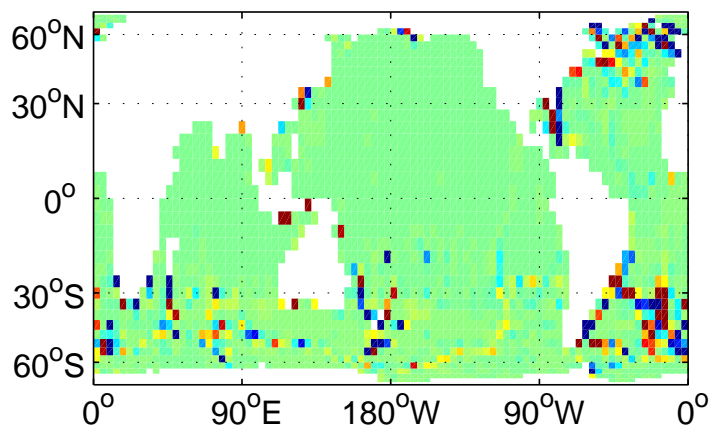

10 years

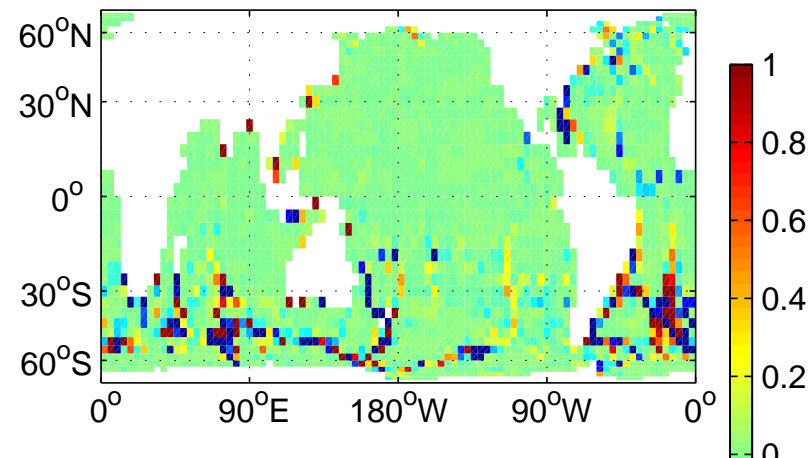

500 years

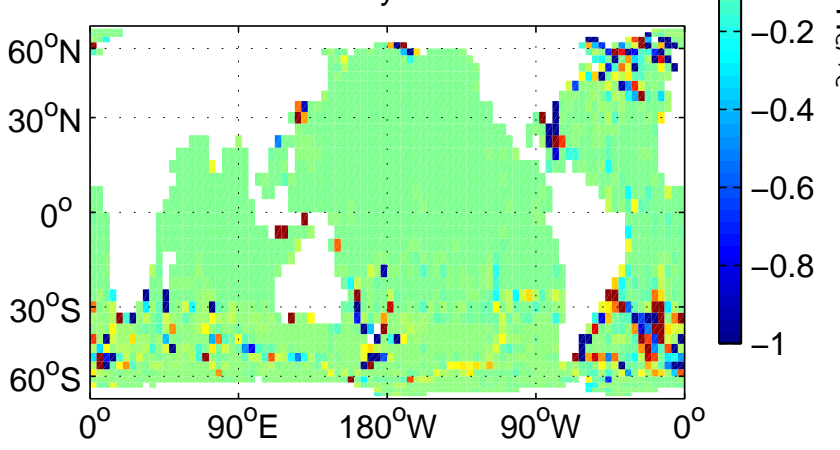

FIG. 4. Adjoint sensitivity of heat transport across $32^{\circ} \mathrm{S}$ to topography for different time scales.

Passage transport by $0.1 \mathrm{~Sv}$ (wind stress), $0.25 \mathrm{~Sv}$ (buoyancy flux), and $0.2 \mathrm{~Sv}$ (topography), that is, by comparable amounts. Clearly, these rough estimates refer to pointwise changes. If we were to estimate the effect of, for instance, large scale wind stress fluctuations in the Southern Ocean, the point-wise effects would accumulate, depending on the error correlation and the topographic effects would be smaller, because uncertainties in topography are likely to be uncorrelated. In the case of perfect correlation, increasing the zonal wind stress south of $38^{\circ} \mathrm{S}$ by $0.05 \mathrm{~N} \mathrm{~m}^{-2}$ implies an integral linear increase of the Drake Passage transport by $20 \mathrm{~Sv}$ consistent with the dramatic increase in transport that Gent et al. (2001) observe when they add $0.05 \times$ secant(latitude) $\mathrm{N} \mathrm{m}^{-2}$ to the zonal wind stress (their experiment $\mathrm{H}$ ). Increasing the heat flux south of $52^{\circ} \mathrm{S}$ by $10 \mathrm{~W} \mathrm{~m}^{-2}$ and assuming perfect correlation increases the transport by $3.0 \mathrm{~Sv}$. Assuming a systematic bias of $+100 \mathrm{~m}$ south of $38^{\circ} \mathrm{S}$ leads to a decrease in transport by $2.1 \mathrm{~Sv}$.

In the other limit of uncorrelated uncertainties wind stress uncertainties of $0.05 \mathrm{~N} \mathrm{~m}^{-2}$ south of $38^{\circ} \mathrm{S}$ lead to $1 \mathrm{~Sv}$ Drake Passage transport uncertainty, heat flux uncertainties of $10 \mathrm{~W} \mathrm{~m}^{-2}$ to $0.5 \mathrm{~Sv}$, and topographic uncertainties of $100 \mathrm{~m}$ south of $38^{\circ} \mathrm{S}$ to $0.6 \mathrm{~Sv}$. We note, that both locally and on the large scale uncertainties in bottom topography can have the same size effect on the Drake Passage transport as uncertainties in surface forcing fields. All effects on the transport have measurable magnitudes and therefore should be controllable. Uncertainties in surface forcing fields are more likely to be correlated in space than topography uncertainties, and the overall effect of surface wind stress uncertainties is estimated to be larger than that of the topography uncertainties.

\section{Discussion}

Numerical ocean models are sensitive to the geometry of the model domain. This sensitivity can be qualified and quantified with the help of an adjoint model that computes the gradient of scalar objective functions (model diagnostics) with respect to the control variables.

We found in a coarse grid configuration of the MITgcm, that the sensitivity with respect to bottom topography is locally equally important to the mean circulation of the model as are surface boundary conditions. Many interesting aspects about the model dynamics are revealed in the sensitivity maps. We have briefly touched upon this topic to illustrate the power of the adjoint sensitivities. To the extent that the model represents real processes, the conclusions about the model dynamics can be transfered to the real ocean.

For future applications of the presented adjoint technology, one can imagine, for example, an objective function that is directly related to the position of the Gulf Stream separation point, thereby finding a way to represent a proper Gulf Stream separation in a coarse model by systematically tuning the topography. Or, extending the work of Köhl (2005), a study on the impact of the topography of the Denmark Strait 

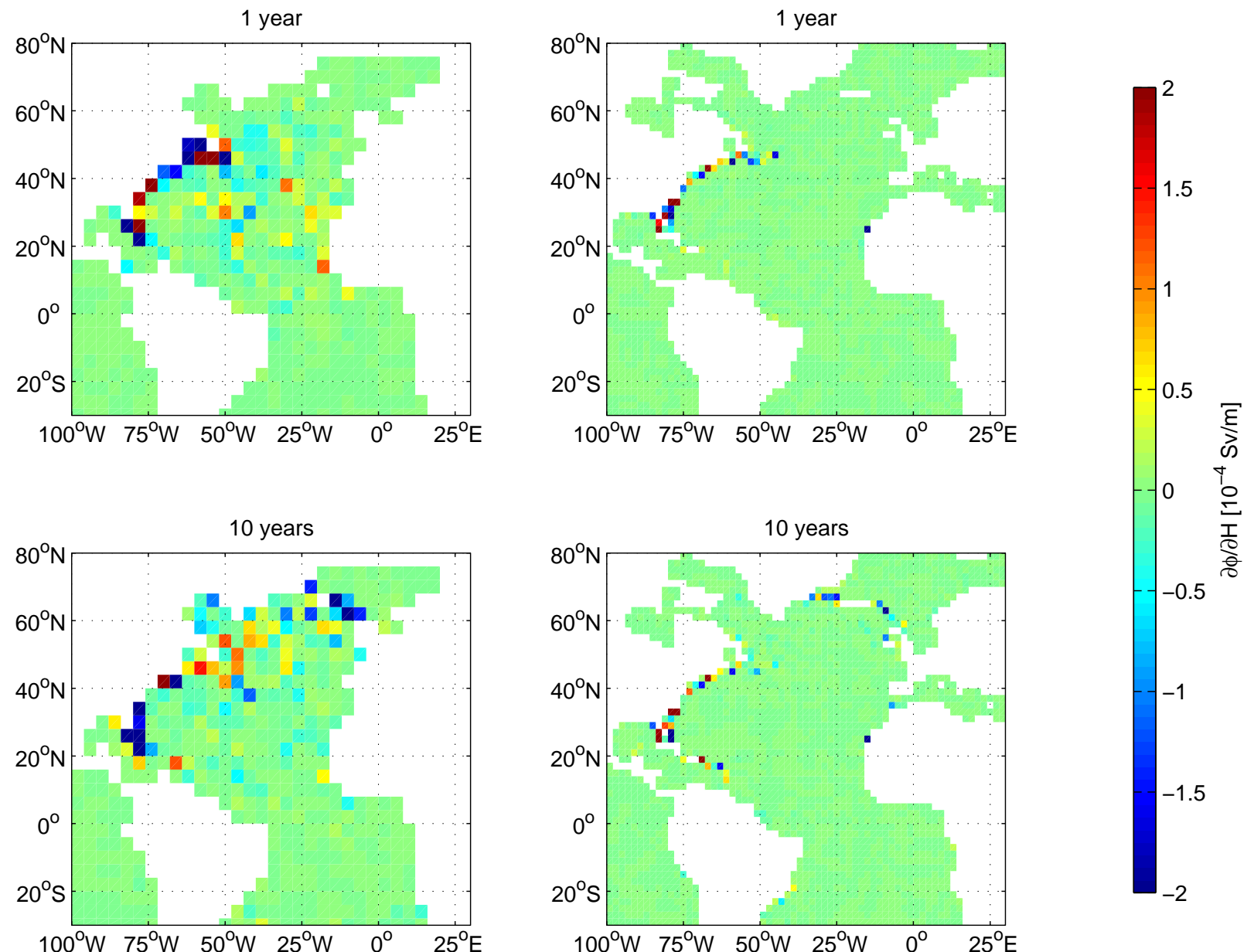

FIG. 5. Comparison of adjoint sensitivity to topography between $4^{\circ}$ (left column) and $2^{\circ}$-resolution (right column) runs for 1 year (top row) and 10 years (bottom row) for the Atlantic meridional overturning stream function.

and the Scotland-Iceland-Ridge could be modified from the traditional approach of changing the topography locally and observing the changes in circulation (e.g., Beismann and Barnier 2004) to asking directly, which control variables affect, say, the Atlantic meridional overturning stream function. Due to the limited resolution of our experiments, we were only able to point to regions where topography matters.

In our simulations, many details are different from realistic scenarios, and necessarily so are the adjoint sensitivities. In the following we name a few.

For computational efficiency, and because this study is in part a proof of concept, we chose a coarse resolution grid, similar to other studies (e.g., Ferreira et al. 2005). We have shown that many of the sensitivity features remain when the resolution is doubled, but have also shown that other features start to change qualitatively (e.g., emergence of a sharper western boundary current structure, and ScotlandIceland Ridge with increasing resolution). Care must therefore be taken to interpret sensitivities within the context of the numerical model and configuration (the issue of convergence of a model towards a solution with increasing reso- lution, may be extended to the question of convergence of adjoint sensitivities, a difficult topic in the context of interpreting adjoint sensitivities in highly nonlinear regimes). In general, we expect that the maps of sensitivity to topography becomes smoother and thus more straightforward to interpret when the resolution increases sufficiently to resolve steep topography gradients. Finally, at eddy permitting resolution, when according to Penduff et al. (2002) roughness of topography can actually lead to less realistic solutions, the sensitivity to topography may be completely different than in our experiments.

With respect to the forcing, we note that imposing constant surface fluxes that are independent of the underlying ocean state is clearly unrealistic. We have chosen this type of idealized boundary condition to facilitate the interpretation of the flux sensitivities. Allowing some feedback between ocean model and surface boundary conditions, for example, by mixed boundary conditions (prescribed fluxes in combination with temperature restoring), both improves the solution and leads to different flux sensitivities, but we found in preliminary experiments that neither restoring boundary conditions nor a seasonal cycle in the boundary conditions 
a) $\partial \phi / \partial \tau_{x}\left[S v m^{2} / N\right]$

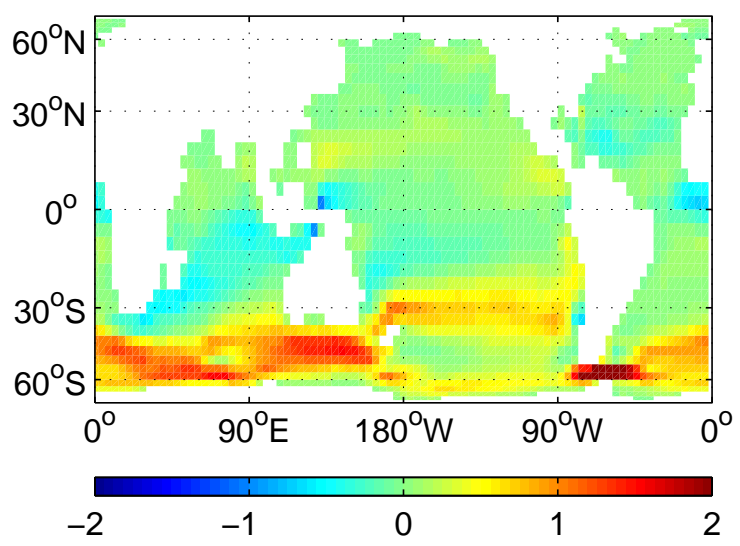

c) $\partial \phi / \partial Q\left[10^{7} \mathrm{~Sv} \mathrm{~s}^{3} / \mathrm{m}^{2}\right]$

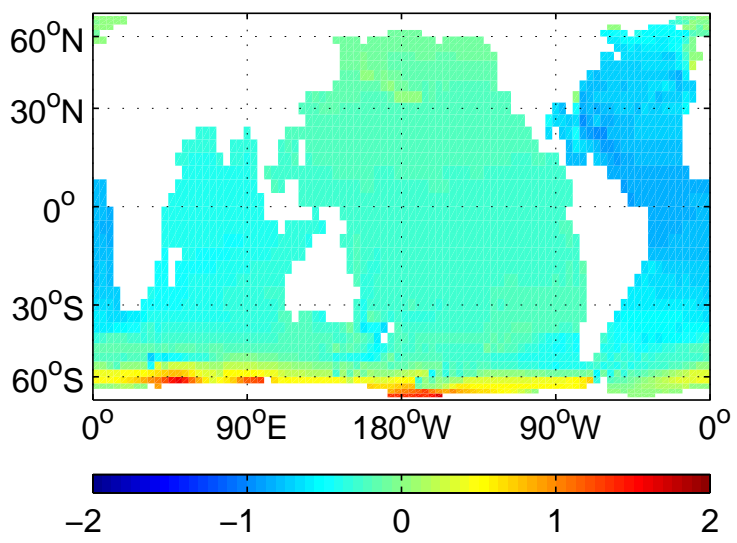

b) $\partial \phi / \partial \tau_{y}\left[S v m^{2} / N\right]$

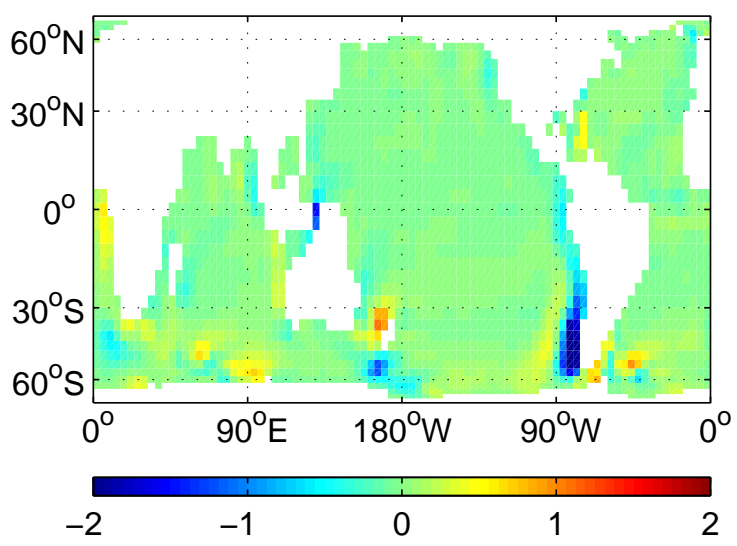

d) $\partial \phi / \partial \mathrm{EmP}\left[10^{7} \mathrm{~Sv} \mathrm{~s}^{3} / \mathrm{m}^{2}\right]$

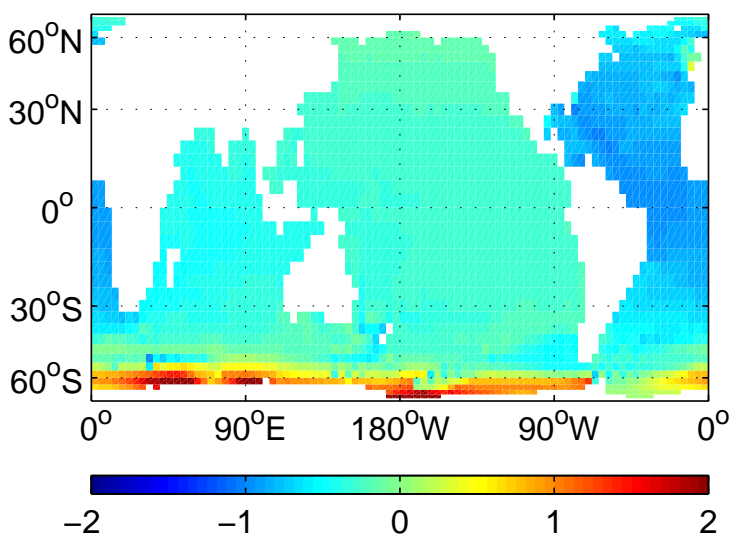

FIG. 6. Adjoint sensitivity with respect to surface boundary conditions of the volume transport through Drake Passage after 100 years: a) zonal wind stress $\tau_{x}$, b) meridional wind stress $\tau_{y}$, c) heat flux $Q$, d) fresh water flux $\operatorname{EmP}$. Heat and fresh water flux sensitivities are rescaled into units of buoyancy flux sensitivity.

have a fundamental effect on the sensitivity to topography (not shown). Using atmospheric state variables such as air temperature, specific humidity and wind speed as control variables, from which surface fluxes are computed via bulk formulae, captures the feedback between atmosphere and ocean even better (as well as the direct coupling between momentum and buoyancy fluxes) and may lead to more realistic sensitivities (efforts in this regards are currently under way in the context of improving the ECCO-like state estimation systems).

For technical reasons, the current model configuration does not include a modern eddy transfer parameterization such as that of Gent and McWilliams (1990), although in principle this is possible (Ferreira et al. 2005, who used an adjoint model with GM-parameterization but without topography as a control variable). Parameterizing turbulent mixing by horizontal diffusion often leads to spurious convection in the Southern Ocean, so the processes in the model that maintain the density structure in the Southern Ocean are different from those in the real world. The southern over- turning cell is most likely affected by this parameterization so that particularly the interpretation of the Deacon cell sensitivities in Section $3 \mathrm{c}$ should not be generalized. On the other hand, the impact of the topography on the near surface flow depends significantly on the oceanic stratification (Marshall 1995b), and one expects a more pronounced impact of the topography at high latitudes regions where the stratification is weak.

Other parameterizations, such as implicit diffusion for deep convection, could also be replaced by more realistic schemes. Parameterizing vertical mixing as a function of topography roughness, following Simmons et al. (2004), adds a further connection between topography and the general circulation. We expect the topography sensitivities to change when including such a parameterization.

Flow near the bottom tends to be affected more strongly by topography than near-surface currents that are baroclinically shielded from the effects of topography (Marshall and Stephens 2001). Either the explicit resolution of such bottom or slope currents or their efficient parameterization, for 
example by a bottom boundary layer model (Beckmann and Doescher 1997, Campin and Goosse 1999) might change the behavior of the ocean model and its sensitivity to bottom topography.

The present findings have consequences for the choice of control variables (the control vector) in ocean state estimation studies. The control variables determine the solution of a model. In state estimation the elements of the control vector are systematically adjusted within prescribed error bounds to fit the model variables to observations. In most of the current state estimation studies the control vector consists of surface boundary conditions and initial conditions. With our findings that bottom topography affects the solution of an OGCM measurably and, at least locally, as much as surface boundary conditions, it is natural to include bottom topography in the control vector and allow it to adjust within prescribed (probably small) limits in the framework of state estimation. Losch and Wunsch (2003) demonstrated the feasibility of this idea in a single-layer, nearlygeostrophic model so that there do not appear to be any fundamental difficulties in doing so. Other parameters, such as mixing coefficients (Stammer 2005), eddy stresses (Ferreira et al. 2005), or lateral slip boundary conditions affect the solution as well and should also be considered. Topography, diffusivity, and lateral boundary conditions promise to be a challenging combination, both technically and dynamically, of control variables in a general circulation model.

Acknowledgments. We thank Carl Wunsch who initiated this work for inspiration and support. ML is grateful for the hospitality of the MIT on several occasions. Sergey Danilov provided many helpful comments. This work was supported in part by the National Oceanographic Partnership Program (NOPP; NASA, NOAA, NSF) through the ECCO Consortium and its follow-on ECCO-GODAE, and by NSF through the ITR program.

\section{APPENDIX}

\section{A. Technical issues of topography as a control variable}

While relying on automatic adjoint code generation, some important issues needed to be addressed. We spare the reader the technical details, but highlight a few conceptual aspects.

The surface pressure field at each time step is found by an implicit scheme. This scheme involves an elliptic matrixoperator and the corresponding equations are solved iteratively. For constant matrix coefficients this operator is selfadjoint, but the coefficients depend on the topography; if bottom topography is a control variable, the operator looses its self-adjoint properties and derivative code for this iterative solver must be generated. Under certain circumstances, the implicit function theorem may be invoked to show that a corresponding iterative solver for the adjoint equations can be derived. However, Giles (2002) shows that straightforward $\mathrm{AD}$ may fail in providing an efficient solver. Here, we chose to store intermediate results of the iteration at each time step.
In the future, this costly approach may be replaced by a more efficient and generally stable solution.

There is a certain freedom in choosing the control variable topography on a C-grid: the topographic height at either the pressure/tracer-points or the velocity points. Because, on a C-grid there are two velocity points per grid cell, the latter choice doubles the number of topography related control variables. It also changes the solution algorithm, implying shaved or cut cells instead of the standard partial cells (Adcroft et al. 1997). Currently, we chose to use topographic height at the pressure/tracers points as control variables instead. This choice involves many non-continuous (non-differentiable) function calls (FORTRAN MIN/MAX functions) when generating the fractional volume cells. The MIN/MAX functions can be replaced by quasi-continuous approximations in order to ensure differentiability. In practice, doing so changes the resulting sensitivities only locally.

\section{REFERENCES}

Adcroft, A., and D. Marshall, 1998: How slippery are piecewiseconstant coastlines in numerical ocean models? Tellus, 50A, 95-108.

Adcroft, A., C. Hill, and J. Marshall, 1997: Representation of topography by shaved cells in a height coordinate ocean model. Mon. Wea. Rev., 125(9), 2293-2315.

Ayoub, N., 2005: Estimation of boundary values in a North Atlantic circulation model using an adjoint method. Ocean Modelling, in press.

Beckmann, A., and R. Doescher, 1997: A method for improved representation of dense water spreading over topography in geopotential-coordinate models. J. Phys. Oceanogr., 27, 581591.

Beismann, J.-O., and B. Barnier, 2004: Variability of the meridional overturning circulation of the North Atlantic: Sensitivity to overflows of dense water masses. Ocean Dynamics, 54(1), 92-106.

Borowski, D., R. Gerdes, and D. Olbers, 2002: Thermohaline and wind forcing of a circumpolar channel with blocked geostrophic contours. J. Phys. Oceanogr., 32(9), 2520-2540.

Bryan, F., 1987: Parameter sensitivity of primitive equation ocean general circulation models. J. Phys. Oceanogr., 17(7), 970-985.

Bugnion, V., 2001: Driving the ocean's overturning: An adjoint sensitivity study, Ph.D. thesis, MIT.

Campin, J.-M., and H. Goosse, 1999: Parameterization of densitydriven downsloping flow for a coarse-resolution ocean model in z-coordinate. Tellus, 51A(412-430).

Das, S. K., and R. W. Lardner, 1991: On the estimation of parameters of hydraulic models by assimilation of periodic tidal data. J. Geophys. Res., 96(C8), 15,187-15,196.

Das, S. K., and R. W. Lardner, 1992: Variational parameter estimation for a two-dimensional numerical tidal model. Int. J. Numer. Methods Fluids, 15(3), 313-327.

Döös, K., and D. J. Webb, 1994: The Deacon cell and the other meridional cells of the Southern Ocean. J. Phys. Oceanogr., 24, $429-442$

Dutkiewicz, S., M. J. Follows, P. Heimbach, and J. C. Marshall, 2006: Controls on ocean productivity and air-sea carbon flux: an adjoint model sensitivity study. Geophys. Res. Lett., 33(2), L02,603, doi:10.1029/2005GL024987. 
Ferreira, D., J. Marshall, and P. Heimbach, 2005: Estimating eddy stresses by fitting dynamics to observations using a residualmean ocean circulation model. J. Phys. Oceanogr., 35(10), $1891-1910$

Ferron, B., and J. Marotzke, 2003: Impact of 4D-variational data assimilation of WOCE hydrography on the meridional circulation of the Indian Ocean. Deep-Sea Res. II, 50, 2005-2021.

Fukumori, I., T. Lee, B. Cheng, and D. Menemenlis, 2004: The origin, pathway, and destination of Niño-3 water estimated by a simulated passive tracer and its adjoint. J. Phys. Oceanogr., 34(3), 582-604.

Galanti, E., and E. Tziperman, 2003: A midlatitude-ENSO teleconnection mechanism via baroclinically unstable long Rossby waves. J. Phys. Oceanogr., 33, 1877-1887.

Galanti, E., E. Tziperman, M. Harrison, A. Rosati, R. Giering, and Z. Sirkes, 2002: The equatorial thermocline outcropping - A seasonal control on the tropical Pacific ocean-atmosphere instability. J. Climate, 15, 2721-2739.

Ganachaud, A., and C. Wunsch, 2000: Improved estimates of global ocean circulation, heat transport and mixing from hydrographic data. Nature, 408, 453-457.

Gebbie, G., P. Heimbach, and C. Wunsch, 2006: Strategies for nested and eddy-resolving state estimation. J. Geophys. Res., submitted.

Gent, P. R., and J. C. McWilliams, 1990: Isopycnal mixing in ocean circulation models. J. Phys. Oceanogr., 20(1), 150-155.

Gent, P. R., W. G. Large, and F. O. Bryan, 2001: What sets the mean transport through Drake Passage? J. Geophys. Res., 106(C2), 2693-2712.

Giering, R., and T. Kaminski, 1998: Recipes for adjoint code construction. ACM Trans. Math. Softw., 24(4), 437-474.

Giles, M. B., 2002: On the iterative solution of adjoint equations. Automatic Differentiation of Algorithms: From Simulation to Optimization, G. Corliss, C. Faure, A. Griewank, L. Hascoet, and U. Naumann, Eds., Springer-Verlag, pp. 145-152.

Griewank, A., 2000: Evaluating Derivatives. Principles and Techniques of Algorithmic Differentiation. vol. 19 of Frontiers in Applied Mathematics, SIAM, 369 pp.

Heemink, A. W., E. E. A. Mouthaan, M. R. T. Roest, E. A. H. Vollebregt, K. B. Robaczewska, and M. Verlaan, 2002: Inverse 3D shallow water flow modelling of the continental shelf. Cont. Shelf Res., 22(3), 465-484.

Heimbach, P., C. Hill, and R. Giering, 2002: Automatic generation of efficient adjoint code for a parallel Navier-Stokes solver. Computational Science - ICCS 2002, J.J. Dongarra, P.M.A. Sloot and C.J.K. Tan, Ed., vol. 2331, part 3 of Lecture Notes in Computer Science, Springer-Verlag, pp. 1019-1028.

Heimbach, P., C. Hill, and R. Giering, 2005: An efficient exact adjoint of the parallel MIT general circulation model, generated via automatic differentiation. Future Generation Computer Systems (FGCS), 21(8), 1356-1371.

Hill, C., V. Bugnion, M. Follows, and J. Marshall, 2004: Evaluating carbon sequestration efficiency in an ocean circulation model by adjoint sensitivity analysis. J. Geophys. Res., 109(C11), C11,005, doi:10.1029/2002JC001598.

Holland, W. R., 1973: Baroclinic and topographic influences on the transport in western boundary currents. Geophys. Fluid Dyn., 4, $187-210$.

Huang, B., P. H. Stone, and C. Hill, 2003: Sensitivities of deep-ocean heat uptake and heat content to surface fluxes and subgrid-scale parameters in an ocean general circulation model with idealized geometry. J. Geophys. Res., 108(C1), 3015, doi:10.1029/2001JC001218.

Jiang, S., P. H. Stone, and P. Malanotte-Rizzoli, 1999: An assessment of the Geophysical Fluid Dynamics Laboratory ocean model with coarse resolution: Annual-mean climatology. $J$. Geophys. Res., 104(C11), 25,623-25,645.

Junge, M. M., and T. W. N. Haine, 2001: Mechanisms of North Atlantic wintertime sea surface temperature anomalies. J. Climate, 14(24), 4560-4572.

Köhl, A., 2005: Anomalies of the meridional overturning: Mechanisms in the North Atlantic. J. Phys. Oceanogr., 35(8), 14551472.

Köhl, A., and D. Stammer, 2004: Optimal observations for variational data assimilation. J. Phys. Oceanogr., 34(3), 529-542.

Köhl, A., and J. Willebrand, 2003: Variational assimilation of SSH variability from TOPEX/POSEIDON and ERS1 into an eddy-permitting model of the North Atlantic. J. Geophys. Res., 108(C3), 3092, doi:10.1029/2001JC000982.

Lardner, R. W., A. H. Al-Rabeh, and N. Gunay, 1993: Optimal estimation of parameters for a two-dimensional hydrodynamical model of the Arabian Gulf. J. Geophys. Res., 98(C10), 18,22918,242 .

Large, W. G., G. Danabasoglu, S. C. Doney, and J. C. McWilliams, 1997: Sensitivity of surface forcing and boundary layer mixing in a global ocean model: Annual-mean climatology. J. Phys. Oceanogr., 27(11), 2418-2447.

Lea, D. J., T. W. N. Haine, and R. F. Gasparovic, 2006: Observability of the Irminger Sea circulation using variational data assimilation. Quart. J. Roy. Meteor. Soc..

Levitus, S., and T. Boyer, 1994: World Ocean Atlas 1994. Volume 4: Temperature. NOAA, NOAA Atlas NEDSIS 4.

Levitus, S., R. Burgett, and T. Boyer, 1994: World Ocean Atlas 1994. Volume 3: Salinity. NOAA, NOAA Atlas NEDSIS 3.

Li, X., and C. Wunsch, 2003: Contraining the North Atlantic circulation between $4.5^{\circ} \mathrm{s}$ and $39.5^{\circ} \mathrm{n}$ with transient tracer observations. J. Geophys. Res., 108(C10), 3318, doi:10.1029/2002JC001765.

Li, X., and C. Wunsch, 2004: An adjoint sensitivity study of chlorofluorocarbons in the North Atlantic. J. Geophys. Res., 109(C1), C01,007, doi:10.1029/2003JC002014.

Losch, M., and C. Wunsch, 2003: Bottom topography as a control parameter in an ocean circulation model. J. Atmos. Oceanic Technol., 20(11), 1685-1696.

Losch, M., A. Adcroft, and J.-M. Campin, 2004: How sensitive are coarse general circulation models to fundamental approximations in the equations of motion? J. Phys. Oceanogr., 34(1), 306-319.

Marotzke, J., and C. Wunsch, 1993: Finding the steady state of a general circulation model through data assimilation: Application to the North Atlantic Ocean. J. Geophys. Res., 98(C11), 20,149-20,167.

Marotzke, J., R. Giering, K. Q. Zang, D. Stammer, C. Hill, and T. Lee, 1999: Construction of the adjoint MIT ocean general circulation model and application to Atlantic heat transport sensitivity. J. Geophys. Res., 104(C12), 29,529-29,547.

Marshall, D., 1995a: Influence of topography on the large-scale ocean circulation. J. Phys. Oceanogr., 25(7), 1622-1635.

Marshall, D., 1995b: Topographic steering of the Antarctic Circumpolar Current. J. Phys. Oceanogr., 25(7), 1635-1650. 
Marshall, D. P., and J. C. Stephens, 2001: On the insensitivity of the wind-driven circulation to bottom topography. J. Mar. Res., 59(1), 1-27.

Marshall, J., A. Adcroft, C. Hill, L. Perelman, and C. Heisey, 1997: A finite-volume, incompressible Navier Stokes model for studies of the ocean on parallel computers. J. Geophys. Res., 102(C3), 5753-5766.

Marsland, S., and J.-O. Wolff, 2001: On the sensitivity of Southern Ocean sea ice to the surface freshwater flux: A model study. $J$. Geophys. Res., 106(C2), 2723-2741.

MITgcm Group, 2002: MITgcm Release 1 Manual. MIT/EAPS, (online documentation), http://mitgcm.org/sealion/ online_documents/manual.html.

Moore, A. M., H. G. Arango, E. D. Lorenzo, B. D. Cornuelle, A. J. Miller, and D. J. Neilson, 2004: A comprehensive ocean prediction and analysis system based on the tangent linear and adjoint of a regional ocean model. Ocean Modelling, 7(1-2), 227-258.

Olbers, D., 1998: Comments on "On the obscurantist physics of 'form drag' in theorizing about the Circumpolar Current". $J$. Phys. Oceanogr., 28(8), 1647-1654.

Olbers, D., D. Borowski, C. Völker, and J.-O. Wolff, 2004: The dynamical balance, transport and circulation of the Antarctic Circumpolar Current. Antarctic Science, 16, 439-470.

Pacanowski, R. C., and G. Anand, 1998: Transient response in a z-level ocean model that resolves topography with partial cells. Mon. Wea. Rev., 126(12), 3248-3270.

Penduff, T., B. Barnier, M.-A. Kerbiriou, and J. Verron, 2002: How topographic smoothing contributes to differences between the eddy flows simulated by sigma- and geopotential-coordinate models. J. Phys. Oceanogr., 32(1), 122-137.

Sheinbaum, J., and D. L. T. Anderson, 1990: Variational assimilation of XBT data. part 1. J. Phys. Oceanogr., 20(5), 672-688.

Simmons, H. L., S. R. Jayne, L. C. St. Laurent, and A. J. Weaver, 2004: Tidally driven mixing in a numerical model of the ocean general circulation. Ocean Modelling, 6(3-4), 245-263.

Sirkes, Z., and E. Tzipermann, 1997: Finite difference of adjoint or adjoint of finite difference? Mon. Wea. Rev., 125(12), 33733378.

Sloss, P. W., 1988: Data announcement 88-MGG-02, digital relief of the surface of the Earth, NOAA, National Geophysical Data Center, Boulder, $\mathrm{CO}$

Sloyan, B. M., and S. Rintoul, 2001: The Southern Ocean limb of the global deep overturning circulation. J. Phys. Oceanogr. 31(1), 143-173.

Smith, W. H. F., and D. T. Sandwell, 1997: Global seafloor topography from satellite altimetry and ship depth soundings. Science, 277, 1957-1962.

Speer, K. G., S. R. Rintoul, and B. M. Sloyan, 1999: The diabatic Deacon cell. J. Phys. Oceanogr., 30(12), 3212-3222.
Stammer, D., 2005: Adjusting internal model errors through ocean state estimation. J. Phys. Oceanogr., 35(6), 1143-1153.

Stammer, D., C. Wunsch, R. Giering, C. Eckert, P. Heimbach, J. Marotzke, A. Adcroft, C. N. Hill, and J. Marshall, 2002: The global ocean circulation during 1992-1997, estimated from ocean observations and a general circulation model. J. Geophys. Res., 107(C9), 3118, doi:10.1029/2001JC000888.

Stammer, D., C. Wunsch, R. Giering, C. Eckert, P. Heimbach, J. Marotzke, A. Adcroft, C. Hill, and J. Marshall, 2003: Volume, heat and freshwater transports of the global ocean circulation 1992-1997, estimated from a general circulation model constrained by WOCE data. J. Geophys. Res., 108(C1), 3007, doi:10.1029/2001JC001115.

ten Brummelhuis, P. G. J., A. W. Heemink, and H. F. P. van den Boogaard, 1993: Identification of shallow sea models. Int. J. Numer. Methods Fluids, 17(8), 637-665.

Toggweiler, J. R., and B. Samuels, 1995: Effect of Drake Passage on the global thermohaline circulation. Deep-Sea Res. I, 42(4), 477-500.

Trenberth, K. E., and J. M. Caron, 2001: Estimates of meridional atmosphere and ocean heat transports. J. Climate, 14(8), 34333443.

Trenberth, K. E., J. G. Olson, and W. G. Large, 1990: The mean annual cycle in global ocean wind stress. J. Phys. Oceanogr., 20, 1742-1760.

Tziperman, E., and W. C. Thacker, 1989: An optimalcontrol/adjoint-equations approach to studying the oceanic general circulation. jpo, 19(10), 1471-1485.

Weaver, A. T., J. Vialard, and D. L. T. Anderson, 2003: Three- and four-dimensional variational assimilation with an ocean general circulation model of the tropical Pacific Ocean. part 1: Formulation, internal diagnostics and consistency checks. Mon. Wea. Rev., 131(t), 1360-1378.

Wunsch, C., 1984: Acoustic tomography and other answers. "It's the water that makes you drunk." A celebration in Geophysics and Oceanography - 1982. In honor of Walter Munk on his 65th birthday., Scripps Institution of Oceanography Reference Series 84-5, Scripps Institution of Oceanography, of California, San Diego, pp. 47-62.

Wunsch, C., 1996: The Ocean Circulation Inverse Problem. Cambridge University Press, 442 pp.

Wunsch, C., 2005: The total meridional heat flux and its oceanic and atmospheric partition. J. Climate, 18(21), 4374-4380.

Wunsch, C., and P. Heimbach, 2006: Practical global oceanic state estimation. Physica D, submitted.

Printed February 18, 2006. 